Association for Information Systems AIS Electronic Library (AISeL)

DIGIT 2007 Proceedings

Diffusion Interest Group In Information Technology

2007

\title{
Impact of Electronic Auctions on Health Care Markets
}

Martin Smits

Tilburg University, m.t.smits@uvt.nl

Richard Janssen

Tilburg University, r.t.j.m.janssen@uvt.nl

Follow this and additional works at: http://aisel.aisnet.org/digit2007

\section{Recommended Citation}

Smits, Martin and Janssen, Richard, "Impact of Electronic Auctions on Health Care Markets" (2007). DIGIT 2007 Proceedings. 8. http://aisel.aisnet.org/digit2007/8

This material is brought to you by the Diffusion Interest Group In Information Technology at AIS Electronic Library (AISeL). It has been accepted for inclusion in DIGIT 2007 Proceedings by an authorized administrator of AIS Electronic Library (AISeL). For more information, please contact elibrary@aisnet.org. 


\title{
Impact of Electronic Auctions on Health Care Markets ${ }^{1}$
}

\author{
Martin Smits (1) and Richard Janssen (2) \\ (1) School of Economics and Business Administration, \\ Tilburg University, PO Box 90153, 5000LE Tilburg, Netherlands, m.t.smits@uvt.nl \\ (2) Tranzo Research Institute for Transformation of Health Care \\ Tilburg University, PO Box 90153, 5000LE Tilburg, Netherlands, R.T.J.M.Janssen@uvt.nl
}

\begin{abstract}
Electronic auctions can be applied in certain markets, but the effects on market structure, market behaviour and market performance are unclear. We analyzed the effects of a reverse electronic auction initiative, implemented by a new intermediary (CareAuction.nl), on the market for maternity care in the Netherlands in 2005 and 2006. After an unsuccessful start in 2004 as cybermediary in the care market between patients and care providers, CareAuction successfully moved in March 2005 to the care contracting market between insurance companies and care providers. We found small but significant effects on the price of maternity care (minus 2-4\%), and significant effects on market structure (more care providers involved in the bidding processes) and market behavior (bidding behaviors and user preferences). We see good opportunities to improve health care market effectiveness for specific care services (non-emergency, elective, standardized care) and to further adapt the auction mechanism.
\end{abstract}

Key words: Auction, Health Care, Market Performance, Intermediation, Cybermediation.

\section{Introduction}

The health care sector is a huge industry in many Western countries. For instance, health care expenditures in the US economy were nearly two trillion dollars per year in 2004 (Smith et al., 2006; CMMS, 2007). Markets play an important role in the delivery and financing of health care in the US (Gaynor, 2005) and the UK (Propper, 2003). Market-oriented healthcare reforms are being considered or enacted in many countries where policymakers have to decide on reforms and regulation, including competition law, while courts and competition regulators have to make decisions about firms in health care markets (Gaynor, 2005). A key reform objective in the European health care systems over the last two decades has been to make the health care system more demand-oriented (Kerzman et al., 2003).

Health care markets exist between users of care (patients or clients), providers of care (e.g., doctors and hospitals), and purchasers of care (e.g., insurance companies) (Propper, 2003). Auctions might play a positive role in matching demand and supply in these markets, offering opportunities to address the vexing concern of ever increasing health care costs, keeping these costs under some control, and assuring quality of care. The electronic auction mechanism might serve as a potential solution to national health care policy dilemmas. Additionally, electronic auctions might lead to the reduction in transaction costs. Transaction costs in health care are high due to the complexity of health services and difficulties in predicting the needs for specific services (Haselbekke et al., 2002).

1 This paper was presented at DIGIT 2007, ICIS December 10 2007, Montreal, Canada. This paper is a preprint of a paper that has been accepted for publication in The International Journal of Electronic Markets, 2008 (http://journalsonline.tandf.co.uk/). 
CareAuction.nl (in Dutch: Zorgveiling.nl) is a recent private initiative in the maternity care sector in the Netherlands. About 30\% of all maternity care was contracted through CareAuction.nl by the end of 2006. In this paper, we analyze the influence of auctions, and more specifically electronic auctions, on health care markets. In this paper, we analyze the influence of the auction principle and more specifically, the electronic auction, on health care markets. Our aim is to assess if and how auctions can help to improve health care systems.

First we develop the theoretical argument based on auction theory, electronic market theory, and the Structure Conduct Performance model for market analysis, taken from industrial economics (Shepherd, 1985). Second, we describe the research method, the background of the health care sector, and how health care services are usually bought. Third, we analyze the effects of the introduction of CareAuction on the maternity care markets in the Netherlands. We conclude with lessons learned from the case about how electronic auctions can help to improve market performance, particularly in the health care sector.

\section{Theoretical Background}

We first review auctions and electronic markets theory. We then introduce the model of Shepherd (1985) to analyze the effects of external determinants (like electronic auctions) on market structure, market behaviour, and market performance. Literature tells us that, if a market is successfully restructured by means of electronic arguments resulting in new market behaviour, there should be changes (improvements) in market performance, but the ability to change market structures is not a foregone conclusion.

\section{Auctions and Auction Mechanisms}

A standard or non-Web auction is defined as "a market institution with an explicit set of rules determining resource allocation and prices on the basis of bids from the market participants" (McAffee and McMillan, 1987) and as 'a market mechanism to match supply and demand of a specific product or service, where one or more customers (bidders) meet one or more suppliers' (Van Heck and Ribbers, 1998). The buyers (bidders) in an auction determine the price for the resource (product or service) and the seller determines the rules of the auction. In contrast, in a 'reverse auction', the sellers of a good or service determine the price and the buyers determine the rules of the auction.

The auction mechanism defines whether bids will be (i) increasing or decreasing, (ii) simultaneous or sequential, and (iii) open or closed. Also, the mechanism determines when and how the auction stops, how bids are compared, how the price is determined, and how the goods are allocated to the winning bidders. Also, rules can be applied for minimum bids and the step sizes for the biddings (Sashi and O’Leary, 2002).

A popular auction mechanism is the English auction or the Ascending Price auction. The seller starts the bidding at a minimally acceptable point usually called the reserve price and the buyers increase their bids until no one is willing to go any higher. The buyer with the highest bid wins the item. Another commonly used auction format is the Dutch auction where bids don't rise, but decrease. The seller offers a product at a high price and lowers the price until one buyer accepts the price (by saying 'mine'). When this mechanism is used to sell multiple items of the same article, it is referred to as a 'discriminatory price auction'. In this auction mechanism, bids are sorted from high to low and the items are allocated to the highest bids until no item is left. Other single item auction types ('Vickrey auctions') are characterized by the rules to choose the winning bid: 'first price auctions' (best bid wins the auction) and 'second price auctions' (second best bid wins). A special auction mechanism is the 'reverse auction' where the buyer 'controls' the market because an item is being requested that is offered by a number of sellers. The price offered by the sellers continues to decrease until a theoretical rational market price is achieved and the (single) buyer accepts the bid of one of the sellers (Smeltzer and Carr, 2003).

\section{Electronic Auctions}

An electronic auction brings buyers and sellers together via some type of electronic media, usually the Internet (Van Heck and Ribbers, 1998). Unlike classical auctions, electronic auctions facilitate the use of multiple criteria simultaneously to evaluate bids, meaning that the auctioneer can aim to reach the best possible price, quality, delivery time, continuity of services, and other performance indicators in one auction (Van Heck and Ribbers, 
1998; Hakamis et al., 2003). An electronic auction can be regarded as an inter-organisational system (IOS) that allows participating buyers and sellers to exchange information about prices and product offerings, supporting their interactions in order to identify, select and execute transactions (Van Heck and Ribbers, 1998). An IOS is maintained and developed by an intermediary (Choudhury et al., 1998). Electronic auctions can lead to the formation of electronic markets.

\section{Electronic Markets}

Hierarchies and markets are two basic structures that control the flow of goods and services within and between organisations, according to the well known Transaction Costs Theory (Williamson, 1985). Classical markets are expensive mechanisms for organisations, because of the high transaction costs for searching, executing, and evaluating market transactions. Organisations (managers) aim to reduce transaction costs by sourcing activities into the organisational hierarchy, which results in larger organizations, until internal transaction costs (hierarchy costs) exceed external transaction costs (market costs) (Williamson, 1985).

IT can have various effects on the trade-off between markets and hierarchies, as hypothesized in several theories (Bakos, 1998; Sarkar et al., 1998). In their Electronic Markets Hypothesis (EMH) Malone et al (1987) state that, by reducing the costs of market coordination, IT will lead to an overall shift toward use of markets -rather than hierarchies- to coordinate economic activity. Critics of the EMH claim more complex effects of IT and advocate the Electronic Hierarchy Hypothesis (EHH) (Johnston and Lawrence, 1988), the Move to the Middle Hypothesis (MMH) (Clemons et al., 1993), and the Threatened Intermediary Hypothesis (TIH) (Benjamin and Wigand, 1995). EHH predicts the growth of electronic hierarchies because IT enables privileged access to market data formed by small groups of vertically arranged companies that develop very close relationships. MMH predicts a market structure between markets and hierarchies, in which companies move toward more outsourcing (i.e., more use of electronic markets), and at the same time build on a reduced set of stable partnerships (i.e., using electronic hierarchies). TIH predicts the decline of traditional intermediaries in the value chain because of IT-enabled data exchange.

Based on these theories, Sarkar et al (1998) developed a theory of electronic value chains, addressing the nature of intermediation in electronic marketplaces and arguing that electronic markets require a more complex set of producer-consumer mediating needs, which in many cases will be best provided by IT-enabled intermediaries operating on the Web (referred to as 'cybermediaries'). More specifically, Sarkar et al. called for research on the impact of IT on market structure (in particular with respect to the roles of intermediaries and cybermediaries) and the evolution of electronic marketplaces.

\section{Effects of Electronic Auctions on Markets}

To evaluate the effects of electronic auctions on markets and how these effects interact, we use the industrial dynamics theory of Shepherd (1985), which distinguishes among four factors that influence each other: market structure, market behaviour, market performance, and external determinants (Figure 1). The general hypothesis of industrial organisation is that market structure affects market performance, as indicated by the thick arrows (Shepherd, 1985, p 7). The influence can either be direct (e.g., in a monopoly the market structure influences prices) or indirect (e.g. the presence of certain actors in the market can influence competitive behaviour, ultimately influencing prices). Shepherd explains that causation can also run the other way (dotted arrows); for example, when a firm makes good profit with a certain product offering, this can lead to new behaviour of other market participants and new market entrants. Also, changes in market structure, behaviour and performance can lead to changes in external determinants (like government policies).

Electronic auctions can have various effects on markets (Kambil and Van Heck 1998, Van Heck and Ribbers, 1998; Ward and Clark, 2002; Sashi and O’Leary, 2002). Electronic auctions affect market structure because they can influence the numbers of market participants: numbers can increase when market accessibility improves, and numbers can decrease if high (IT) investment are needed for market participants (entry and exit barriers). Market behaviour can be influenced because more market information can be made available to all or some market participants (information symmetry or asymmetry), and because multiple transactions and different auction mechanisms can be used to exchange smaller batches, for specific buyer groups, either sequentially or simultaneously. Market performance can be influenced because electronic auctions can lead to lower transaction costs, more transactions per hour, and more complex transactions can be executed because of the use of auction- 


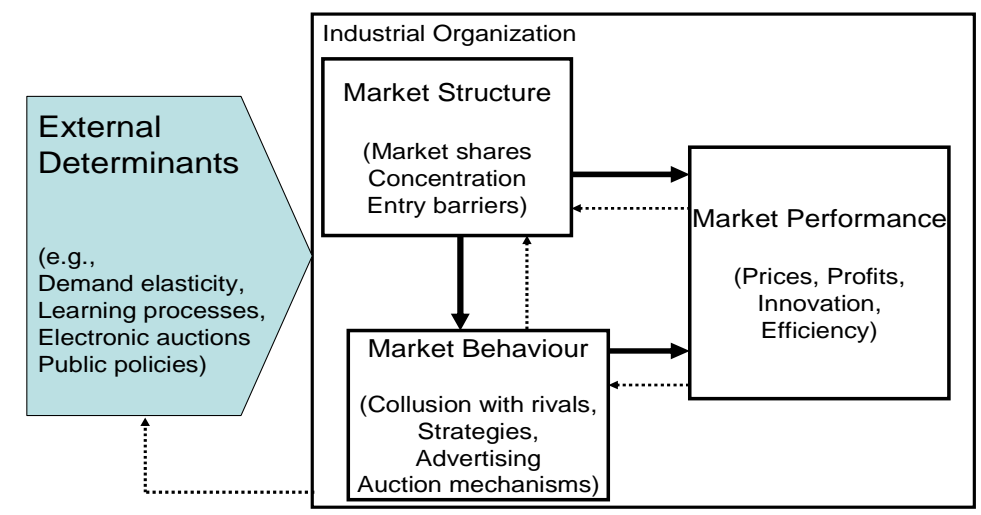

Figure 1. External determinants influence Market Structure, Behaviour and Performance (based on Shepherd, 1985)

robots (Pinker et al., 2003). Auction mechanisms can also affect markets. For example, reverse auctions tend to lead to lower prices and faster transactions (Smeltzer and Carr, 2003), English auctions to lower prices (Bulow and Kemperer, 1996), and Dutch auctions to more transactions per hour and higher prices (Kambil and Van Heck, 1998).

The Shepherd theory helps us to address the impact of IT (as external determinant) on market structures and evolution of marketplaces (as proposed by Sarkar et al,1999) because the theory focuses on the development of markets and the dynamic interactions among market structure, conduct, and performance. Evolution of a market is presumed to follow a certain sequence; Daniel and Klimis (1999) evaluated market developments in the retail financial services industry and the music industry in order to determine the validity of Malone et al.'s EMH. They propose that electronic markets develop from classical markets, going through 'a biased market' (where services are available from a number of suppliers), to an 'unbiased market' (where services are available from all suppliers), to a 'personalized market' (where personalized decision aids help buyers), ending in a 'reverse market' (where buyers publish their needs over the electronic medium, where suppliers then bid to win their business). Daniel and Klimis hypothesized that the use of electronic markets enhances the power of buyers.

\section{Research Method}

Our research method is qualitative and consists of a retrospective analysis of one case, based on structured interviews with different actors involved in the changing care markets, experiencing and reacting to the effects of the electronic auction system (Klein and Myers, 1999). In-depth analysis of one case is an appropriate research strategy when it is difficult to separate a phenomenon (market performance) from its context (market context, structure, and behaviour) (Yin, 1994). Myers (2007) distinguished between three types of qualitative research in information systems (positivist, interpretist, and critical) and four research methods (action research, case study research, ethnography and grounded theory). This research is not action research, because we did not participate in the design and development of the CareAuction website, and our findings did not influence the design during the period investigated. Our case study research can be regarded as positivist but critical (since we bring to light restrictive and alienating conditions of the status quo) (Mingers, 2001). Our research data are (i) the CareAuction usage statistics (made available for us in the CareAuction transaction databases), (ii) background materials such as the NIVEL report on the maternity care sector (Lamkaddam and Wiegers, 2004) and the report on CareAuction by the Dutch Government (Zorgautoriteit, October 2006), and (iii) face-to-face interviews with care providers (four CEOs of maternity care organisations), care purchasers (two senior managers in two large health insurance companies that purchase maternity care for their clients), and the CEO of CareAuction.nl. Each interview took about 90 minutes and was based on a set of open questions on changes in: 
- Market structure. Example questions are 'which market participants were involved?', 'How were demand and supply matched?', 'What is the role of patients before and after using CareAuction?';

- Market behaviour. Example questions are 'has CareAuction influenced your business operations?', 'How do you evaluate the performance of CareAuction?', 'Does CareAuction offer sufficient opportunities to show your specific services?',

- Market performance. Example questions include 'how much time (costs) is needed to use CareAuction (and is this more or less than before)?', 'What are the (dis-) advantages of using CareAuction?'

\section{Auctions and Markets in Health Care}

Auctions are relatively unknown in health care. Some initiatives that resemble CareAuction.nl are www.medicineonline.com, where the reverse auction mechanism is used for cosmetic surgery services. Patients (customers) enter their requests for surgery on line, and surgeons bid by listing their prices and quality indicators such as their educational backgrounds, experiences, and surgical facilities. Other examples of auctions in health care are related to non-treatment activities, such as a Dutch hospital that uses an auction to outsource sterilization services (achieving 30\% cost reduction), or a group of hospitals that outsource copying services, or hospitals that use auctions to purchase office supplies and surgical gloves (www.nvilg.nl 2003, 2004).

\section{Care Purchasing Processes}

Care insurance companies in the Netherlands are responsible for the supply of sufficient quantities and quality of care, as needed by their insured customers and meeting the requirements of national authorities and laws. Traditionally, care insurance companies purchase care services for fixed prices by contracting care providers for bulk contracts for longer periods of time. The Dutch Health Insurance Act ('Zorgverzekeringswet') - the new health care policy since September 2004- allows insurance companies and care providers to negotiate on price and quality of health services, but contracts are still typically based on fixed prices and for one year care volumes. Individual patients receive care from individual care providers, after which the insurance company pays the bill based on fixed prices. Each care provider can have contracts with multiple insurance companies, and each insurance company can contract multiple care providers (to allow freedom of choice for their insured clients). Insurance companies can use 'preferred suppliers' to deliver all care to the clients in the core geographical areas of the insurance companies. For care outside their core areas, insurance companies in the Netherlands contract 'care brokers' (such as LTZ and ZUN for maternity care). Care brokers are intermediaries in the care contracting market that resell care to insurance companies.

\section{The CareAuction Case}

CareAuction is a private initiative and a small (8 full time equivalent staff) privately owned (dotcom) company aiming to enable Internet based auctions for care and care related products and services. The Internet application (www.zorgveiling.nl) was developed in 2003 and the application has been used since March 2005 by two large health insurance companies in the Netherlands (Achmea and Menzis) to purchase maternity care services for their clients (patients). The other eight health insurance companies have decided not (yet) to use CareAuction. We analyze the market changes for the two insurance companies that participated in CareAuction.

Originally, CareAuction was intended to increase the power of patients, helping them to influence care services, to increase customization, competition and quality of services. In Figure 2, this would mean that CareAuction would be positioned in the (business to consumer) care market between care providers and patients. Since this positioning resulted in too many dispersed customers, a high administrative load for the CareAuction organisation, and limited enthusiasm of customers (since they gain no clear benefits from the auction), CareAuction decided to position itself in the (business to business) care contracting market between insurance companies and care providers. As of 2005, CareAuction offered a variety of tools (robots) to insurance companies and care providers, facilitating the business to business market. In this way, CareAuction has deployed IT to change the purchasing processes of insurance companies. Contracts with care providers are no longer made once per year per provider (stating the yearly volumes and prices of care), but instead are made 200 days per year, per individual request, varying in price. 


\section{The auction mechanism}

The essence of the CareAuction procedure is that insured customers (or clients or patients) report their needs for maternity care services to their insurance company. The insurance company enters the need into the CareAuction web-application and care providers start bidding. This auction mechanism is a reverse English auction. Reverse because the demand for (and not the supply of) care services is auctioned. English, because the bids (reductions of the maximum price) are raised until no one wants to bid higher (within the maximum auction period of three or five days). The bidding process is transparent to some extent: All bidders are informed about new bid, but the identity of the bidders is not disclosed.

The auction mechanism is a process consisting of three stages: the care request stage, the bidding stage, and the allocation stage. The request stage for maternity care starts when the patient (client) contacts the call center of the insurance company, usually 5--6 months before the birth is expected. (Note that clients who contact a care provider must be referred to the insurance company.) Standard maternity care consists of 44 hours of home care, divided over five days for a total tariff of 1,522 Euro (2006), not including the additional payment of about 150 Euro by the patient. The request is specified (amount of maternity care hours in a specific period--immediately after the expected birth date--in a certain postal code area) and entered into the CareAuction web application. Clients can specify one or two preferred care providers, to be chosen out of the providers that are contracted in their region. Clients can also indicate negative preferences (Hoeksema et al., 2006).

The bidding stage starts at midnight after all requests of that day have been checked by CareAuction. Care providers use search filters to find relevant care requests and are contractually bound to bid at least once on each request in their regions. (Note that this means that if providers delay bidding, they may be stuck with a highly unfavorable outcome). Care providers must make their bids within five days (Achmea) or three days (Menzis). Bidding implies that the provider must deliver care if the bid wins the auction. The start tariff in each auction equals the maximum hourly tariff, as determined yearly by the government. The minimum bid is 10 euro (Achmea) or 5 euro (Menzis) on the total number of hours requested. Care providers can use a bidding robot ('autobid') that follows the bidding process and raises a bid (meaning that the price goes down) in steps of 5 euro (other step sizes can be determined by the provider) until a maximum bid has been reached (determined by the provider). A maximum bid is determined by the insurance company to ensure a minimum quality level.

The allocation stage is automated using a robot that allocates care to the best bid. First priority is that a request is allocated to the bid hat was done by the care provider of choice, even if this bid is not the best price. If the client has not listed provider preferences, then the provider with the highest quality ranking is selected (the quality

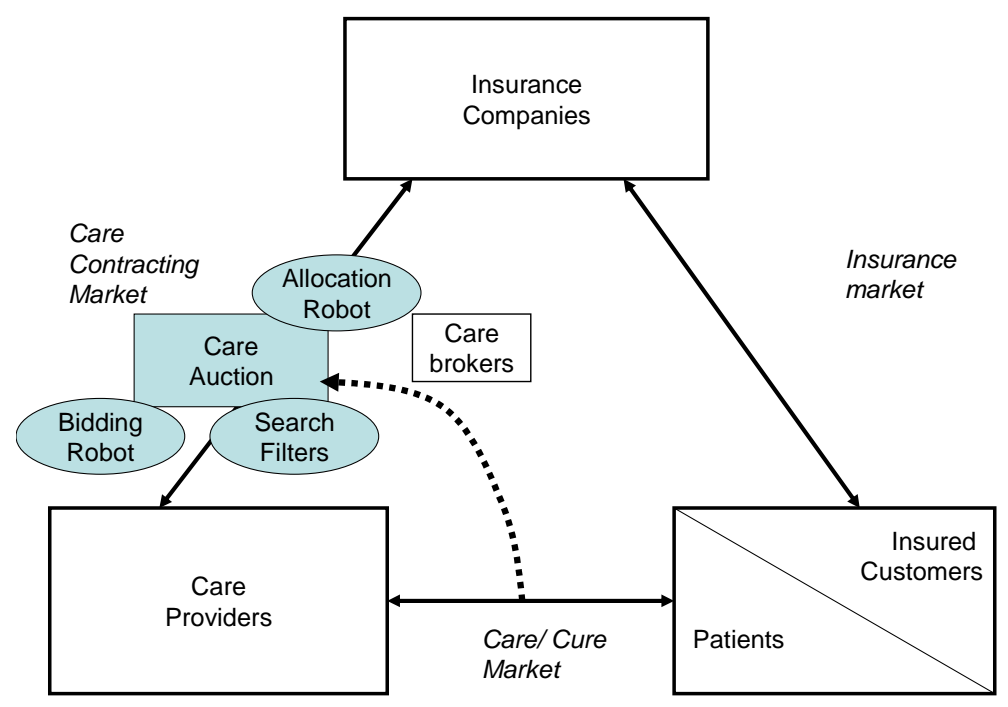

Figure 2: The position of CareAuction as intermediary in the care contracting market. (the dotted arrow illustrates the repositioning of CareAuction between 2004 and 2005) 
system is based on client satisfaction ratings, but was not yet operational in our test period). If customer preference and quality scores do not result in a match, then the request is allocated to the best price (the lowest total price).

After the allocation has been made, the insurance company and the winning care provider automatically receive an email listing the terms and details of the agreement. Clients and insurance companies do not pay for CareAuction intermediary services. Care providers pay a fixed fee per contract (19,50 Euro) to CareAuction. After the care has been delivered, CareAuction sends an evaluation form to the client, which forms the basis for the quality system.

\section{Portal functionality}

The CareAuction portal offers specific functionalities to two distinct groups. Users enter the home page and have to $\log$ in as a care provider or as an insurance company. Typical functionalities are (i) the filtering and sorting of care requests, bids, and contracts, (ii) bidding robots, (iii) automatic messaging to alert bidders on new bids by competitors, (iv) news updates and news letters. One insurance company uses the automatic billing functionality; the other company uses manual conversion of data between the CareAuction application and the internal IT systems. No automatic billing facilities or digital interfacing are offered to care providers. Some effort has been made to improve electronic data interchange, but this effort has stopped because of high costs and lack of shared standards. No functionalities are offered to patients (yet).

\section{Analysis of CareAuction effects}

The introduction of the electronic CareAuction in 2005 has resulted in the emergence of an electronic market for maternity care in the Netherlands. We analyze the effects of the electronic auction on the structure, behaviour, and performance of the markets for maternity care and determine its evolutionary path.

\section{Effects on Market structure}

The market size for maternity care in the Netherlands has been relatively stable over the past decade with about 200,000 childbirths per year, varying from about 12,000 to 20,000 requests per month with seasonal peaks (Statline.CBS.nl). The ten insurance companies in the Netherlands purchase the requested volumes of maternity care. There are about 8000 maternity care providers (5000 full time equivalents) in the Netherlands, employed by about 220 maternity care organisations. The majority (72\%) of these organisations are small firms operating from one location. Only $21 \%$ of all firms operate from two to five locations, and only $7 \%$ have more than 6 locations. Seasonal shortages of care exist in some regions, but these are solved by using flexible contracts with the part time workforce or not fully qualified trainees (Lamkaddam and Wiegers, 2004).

Market participants. Two large insurance companies, Achmea and Menzis, with a combined market share of about 50\% (100,000 births per year) of all maternity care in the Netherlands and about 160 care provider organisations (out of a total of about 220 in the Netherlands) have participated in CareAuction since March 2005. Achmea and Menzis decided not to buy all maternity care through CareAuction, but only the care needed in the peripheries of their business areas, about 15,000 births per year. The core areas are still serviced by using bulk contracting, meaning a fixed price (per hour) equal to the maximum tariff as determined by the Dutch government for a set number of patients per year.

Before 2005, 65\% of all care requests were allocated by the insurance companies to the preferred supplier, and $35 \%$ were allocated through brokers. With the introduction of CareAuction, care brokers can be bypassed. In 2005, CareAuction was used for 7\% of all requests, to some extent by bypassing the brokers. In 2006, CareAuction handled $20 \%$ of all requests, including all care requests in peripheral regions. This means that in 2006 the two insurance companies used the CareAuction cyberrmediary to bypass all (non-electronic) intermediary brokers.

Accessibility. CareAuction operates on a closed market: only care providers that have a contract with one of the two insurance companies are allowed to participate in CareAuction. However, since more than $90 \%$ of all 
maternity care providers operate in the service areas of the two insurers, CareAuction is accessible for almost all providers. Actually, the accessibility of the market has improved since the introduction of CareAuction, because insurance companies used to purchase care through intermediaries (care brokers). Through CareAuction insurers can contact more care providers directly, and care providers can now bid on each request individually, instead of simply waiting to be allocated a request by an insurance company or a broker. CareAuction has improved the accessibility of the care market for patients to some extent: patients can now indicate a preferred supplier but without access to the offerings made by suppliers.

Products. CareAuction operates in a vertical market for one product (maternity care) in one industry (health care). The maternity care market is a homogeneous market with low product variety. The standard product consists of home care of mother and child and some housekeeping for 40 hours over five days. CareAuction has not affected product variety, but insurance companies and care providers expect changes in the near future to allow for more customized care. In addition, maternity care might be combined with other home care services auctioned via CareAuction.

Transparency. CareAuction has increased market transparency for care providers. Before the introduction of CareAuction, each request for care was allocated (and made visible) to only one care provider without providing information about these requests to other care providers. With CareAuction, all providers can see which care requests are made in which region (postal codes) and periods. Care providers find this information not sufficient and would like to see more details per request, including client preferences. Knowing about client preferences would influence their bidding behaviour (such as 'if a client has indicated a preference, high bids are not needed' and 'if a client has not indicated a preference and if region and timing of the request fit the providers' profile, then high bids are attractive).

\section{Effects on Market Behaviour}

Preferences. In the early weeks of CareAuction (between March and July 2005), 61--67\% of care requests included a preferred supplier. In July 2005 until the end of the test phase (February 2006), this percentage suddenly jumped to $81--87 \%$. This jump is explained by care providers instructing their clients to add them as a preferred supplier to the request submitted to insurance companies. Care providers gave this advice to their clients to ensure that they had a good chance of being able to provide the requested services; otherwise, the auction mechanism could easily allocate a care provider's patients to the best bidder. Apparently, clients have followed their providers' advice. (Clients do not have access to on line information about quality of care providers.)

Bidding behaviour. Per auction, eight care providers (2006 average) participate in the bidding. In July 2005, the average bid by care providers on CareAuction was $11.7 \%$, meaning that they offered care for a price of $11.7 \%$ below the normal (maximum) tariff. The average winning bid was $4.3 \%$. This difference is attributable to clients indicating a preferred supplier in response to their providers' advice. In January 2006, the average bid had decreased to $10.2 \%$ and the average winning bid had decreased to $2.6 \%$. This strong reduction in average winning bid was not due to increased requests for preferred suppliers (87\% in July 2005 and 82\% in January 2006). Apparently, suppliers had decided not to make high bids anymore, possibly because they knew by then that most clients would indicate a preference, making high bids unnecessary and expensive.

Drivers for using CareAuction. The insurance companies indicated that they decided to use CareAuction because it provides opportunities for allocating care to preferred suppliers, to achieve better prices, and to introduce a system to assess customer satisfaction. Three out of four care providers do not regard CareAuction as a success: they see it as a cost factor and an administrative burden, and they are not satisfied with the auction system. However, the volume of care requested through CareAuction is so high (up to $30 \%$ market share) that care providers simply cannot afford to disregard the auction. They are forced to use the auction system because of their contracts with the insurance companies.

Business processes. The insurance companies' and the care providers' business processes had to be changed: Insurance companies had to adjust their call center processes to be able to enter individual requests into the CareAuction web application and to remove the requests after the auctions were finished. Care providers have indicated that they would like to have more information per request to help them to decide about bids. They would also prefer care requests with preferred supplier to be allocated directly to the supplier, without being put on auction (so that care providers would receive the maximum allowable reimbursement). However, the insurance companies have decided that all requests must be auctioned, including requests with preferences. 
Billing system. Care providers who win the bid on a care request from the Achmea insurance company have to use the online CareAuction billing system as well as their internal billing system. Double data entry means rekeying the contract data, leading to higher transaction costs for these care providers. The other insurance company does not require double data entries, suggesting that higher transaction costs are due to the Achmea decision and not to the CareAuction application.

\section{Effects on Market Performance}

Price. Because of CareAuction, fixed prices for maternity services no longer exist: CareAuction has resulted in variable prices per care request. The prices are now $2.6 \%$ to $4.3 \%$ lower than the maximum tariff, which used to be the standard tariff in the past (see also 'bidding behaviour'), resulting in estimated savings of 3 million euro in 2007 for the two insurance companies.

Volume. Obviously, CareAuction has not influenced total market size, because the number of clients requesting maternity care is not a function of CareAuction. However, CareAuction has resulted in a significant increase of the number of auctions for maternity care. In April 2005, 800 auctions were done. This number increased to 1400 auctions per month in the period August 2005 to January 2006. In May 2006, about 20\% of all requests for maternity care were auctioned through CareAuction, and this figure is expected to rise to 30\% in 2007.

Quality. During the test period, no changes in the quality of care were found. The insurance companies and the care providers expect quality improvements after implementation of the customer satisfaction evaluation system. We also did not find changes in product variety: maternity care was offered only as a standard service (40 hours in five days), with nonew options for additional qualities that customers might be willing to pay for.

Costs. The introduction of the CareAuction intermediary has influenced various costs of matching care providers to care requests. In a maternity care market of about 150 million Euro per year the costs of CareAuction are about 2 million Euro for transaction fees (100,000 transactions a 19 Euro). These transaction costs are paid by the care providers, who also pay higher internal processing costs and receive less revenue for their services ( $2-4 \%$ of 150 million Euro). So, the net effect for care providers is negative. The net effect of CareAuction for insurance companies is positive: the new call center costs are compensated by benefits such as the elimination of commission costs for care brokers and intangible benefits due to increased transparency.

\section{Discussion and Conclusion}

The health care sector is characterized by three interrelated markets (the care market, the care contracting market, and the insurance market). CareAuction is a new web-based intermediary (a cybermediary) offering a reverse auction system for relatively simple care services (maternity care) in relatively small regional markets. After an unsuccessful start as cybermediary in the care market between patients and care providers in 2004, CareAuction successfully moved to the care contracting market between insurance companies and care providers in March 2005. By the end of 2006, 30\% of all maternity care in the Netherlands was allocated on an individual basis (instead of yearly bulk contracts) through CareAuction, instead of through physical intermediaries (care brokers).

CareAuction has significantly influenced market structure (care brokers disappeared; improved accessibility for providers, increased competition (8 bidders per request instead of one bidder per request), increased transparency, increased power positions for the insurance companies to control care transactions), changed market behaviour (more patient preferences, different bidding behaviour, problems with linking internal and external business processes), and altered market performance (no more fixed prices, increasing transaction costs for providers, and increasing the numbers of transactions through CareAuction to 2000 per month with no changes in the quality of care). Another aspect of market performance is the price per service. We found only a slight reduction (2--4\%) in the price for maternity care, due to the fact that $80 \%$ of the care requests were allocated based on preferences (preferred providers). If care had been allocated on the basis of best price, a price reduction of about $11 \%$ would have been realized.

The CareAuction case shows that electronic auctions can be successfully applied to the market for maternity care, resulting in stronger market positions and more transparency for the two insurance companies that decided to use it. Limited improvements were found for care providers and clients/ patients. Further adjustments to the auction 
mechanism (for instance, by asking the customers to list more than one preferred supplier) might lead to more transparency for all parties and market improvements, including better prices, higher quality, and product differentiation.

The CareAuction case also illustrated the complex interactions between market structure, behaviour and performance. Changing market behaviour (in the form of using a reverse electronic auction mechanism with a specific procedure for matching supply and demand) affects market structure (some buyers and many suppliers enter the electronic market) and market performance (lower prices), which in turn again affects market behaviour (consumers start preferring certain suppliers), ultimately affecting market performance (higher prices).

In 2006, CareAuction did not (yet) provide a quality (or customer satisfaction) system, so it was not possible for a care request to be allocated to a care provider based on quality indicators. Insurance companies and care providers preferred quick implementation of the system because they believe it would result in a fairer allocation of care. They also prefer additional functionalities of the CareAuction application, such as improved management information for providers and insurance companies and improved linkages of the bidding robots to the internal accounting and business systems (because such linkages would reduce transaction costs and enable better planning of work and resources). More research is needed to evaluate the effects of changes in the auction mechanism including the IT functionalities on the intra-and inter-organisational business processes and how these changes affect market structure, behaviour, and performance. Insight into these complex relations is valuable for all actors involved, including health care authorities and for national health policy.

\section{References}

Bakos Y. (1998): The emerging role of electronic market places on the Internet. Communications of the ACM. 41 (8) 35--42.

Benjamin R. and Wigand R. (1995): Markets and virtual value chains on the information superhighway. Sloan Management Rev. 36 (2) 62--72.

194.

Bulow J. and Klemperer P. (1996): Auctions Versus Negotiations. American Economic Rev. 86 (1) 180--

Choudhury V., Hartzel K.S., Konsynski B.R. (1998): Uses and Consequences of Electronic Markets: An Empirical Investigation in the Aircraft Parts Industry. MIS Quarterly, 22 (4) 471--507.

Clemons E.K., Reddi S.P., Row M.C. (1993): The impact of IT on the organisation of economic activity: the move to the middle hypothesis. J of Management Information Systems (10) 2: 9-29

CMMS (2007): Centers for medicare \& medicaid services, Office of the Actuary, National Health Statistics Group, National Health Accounts (www.cms.hhs.gov)

Daniel E., Klimis G.M. (1999): The impact of electronic commerce on market structure: an evaluation of the electronic market hypothesis. European Man. J. 17 (3) 318--325.

EU (2004): Directive on the coordination of procedures for the award of public works contracts, public supply contracts and public service contracts. Official Journal L 134, April 30, 0114 -- 0240

Gaynor, M. (2004): Competition and Quality in Health Care Markets: What Do We Know? What Don't We Know?' Economie Publique 15(2):87-124.

Hakamis M, Teich J.E., Wallenius H, and Wallenius J (2003): An experimental comparison of a traditional English clock auction and a web-based auction in a multiple unit environment. Int. J. of Electronic Markets 13 (3) 233--241

Haselbekke, B.J., Kertzman E., Janssen R.T.J.M. (2002): Contracteren op de markt van ziekenhuiszorg. Acta Hospitalia. 4: 20--30.

Hoeksema, Homans and Menting (2006): Toesting van het instrument Zorgveiling. Rapportage aan Achmea en Menzis. Organisatieadviseurs, Enschede., Netherlands.

Johnston R., Lawrence P.R. (1988): Beyond vertical integration - the rise of the value of adding partnerships, Harvard Business Review. July-August.

Kambil A. and E. van Heck (1998): Re-engineering the Dutch Flower Auctions: A Framework for Analyzing Exchange Organisations. Information Systems Research. 9 (1) 1--19.

Kerzman E., Janssen R., and Ruster M. (2003): E-Business in health care: does it contribute to strengthen consumer interest? Health Policy 64: 63--73.

Klein H.K. and Myers M.D. (1999): A set of principles for conducting and evaluating interpretive field studies in information systems. MIS Quarterly 23 (1) 68--93. 
DIGIT 2007: AIS Special Interest Group on Adoption and Diffusion of IT (SIGADIT). page 11/11

Lamkaddem M. And Wiegers T. (2004): Monitoring Kraamzorg (In Dutch). NIVEL (Dutch Institute for Health Care Research) Report. ISBN 90-6905-662-3. Utrecht, Netherlands.

Malone, T.W., J. Yates, and R.I. Benjamin (1987), Electronic Markets and Electronic Hierarchies. Communications of the ACM. 30 (6) 484--497.

McAfee, R.P. and McMillan, J. (1987): Auctions and Bidding. Journal of Economic Literature. 25 (2) 699--738.

Mingers, J. (2001): Combining IS Research Methods: Towards a Pluralist Methodology. Information Systems Research 12 (3) 240-259.

Myers M.D. (2007): Qualitative Research in Information Systems. IS-World section www.qual.auckland.ac.nz.

Pinker, E.J., Seidmann, A., and Vakrat, Y. (2003): Managing online auctions: current business and research issues. Management Science. 49 (11) 1457--1484.

Plattel, J. (2006). Europese aanbestedingswetgeving gemoderniseerd. http://www.promereor.nl/Actueel/ Nieuwe_regelgeving_europese_aanbestedingen.htm. Accessed 20 May 2007.

Propper C. and Wilson, D. (2003): The use and usefulness of performance measures in the public sector. Oxford review of economic policy. 19 (2) 250--267.

Sashi C.M., O'Leary B. (2002): The role of Internet auctions in the expansion of B2B markets. Industrial Marketing Management. 31: 103--110.

Sarkar M., Butler B., Steinfield C. (1998): Cybermediaries in electronic marketspace: toward theory building. J. of Business Research. 41: 215--221. Cliffs (NJ).

Shepherd W.G. (1985): The economics of industrial organisation. $2^{\text {nd }}$ ed. Prentice Hall, Englewood

Smeltzer, L.R. and Carr, A.S. (2003): Electronic reverse auctions: Promises, risks and conditions for success. Industrial Marketing Management 32, 481--488.

Smith, C., Cowan, C., Heffler, S., and Catlin, A. (2006). National health spending in 2004: Recent slowdown led by prescription drug spending. Health Affairs, 25 (1) 186-196.

Van Heck E. and Ribbers P. (1998): Introducing electronic auction systems in the Dutch flower industry: comparison of two initiatives. Wirtschaftsinformatik. 40 (3) 223--231.

Ward S.G. and Clark J.M. (2002): Bidding behaviour in on-line auctions: an examination of the eBay Pokemon Card Market. Int. J. of Electronic Commerce. 6 (4) 139--155.

Williamson O.E. (1985): The Economic Institutions of Capitalism. The Free Press, New York. Publishing.

Yin R (1994): Case study research: Design and methods (2nd ed.). Thousand Oaks, CA: Sage

Zorgautoriteit (2006): Rapport Zorgveiling: een onderzoek naar het veilen van kraamzorg (In Dutch). Report of the Dutch Healthcare Authority, Utrecht, Netherlands (www.nza.nl). 